\title{
Experimental Arterial Thromboembolism in Baboons
}

\author{
MECHANISM, QUANTITATION, AND PHARMACOLOGIC PREVENTION
}

\author{
Laurence A. Harker and Stephen R. HANSon, with technical assistance of \\ Thomas R. KIRKman, Departments of Medicine (Hematology), Chemical \\ Engineering, and The Regional Primate Center, University of Washington \\ School of Medicine, Seattle, Washington 98195
}

A B S T RAC T A quantitative primate model of arterial thromboembolism has been characterized with respect to mechanism and usefulness in evaluating modifying variables. The model involved the kinetic measurements of ${ }^{51} \mathrm{Cr}$-platelets and ${ }^{125} \mathrm{I}$-fibrinogen consumption by femoral arteriovenous cannulae in chaired baboons.

Cannula platelet consumption correlated directly with exposed cannular area for irradiated Silastic and polyurethane (correlation coefficients of 0.940 and 0.901 , respectively; $P<0.001$ ) and remained steady state for months. Nonirradiated Silastic was only minimally reactive with platelets. Despite increased rates of platelet consumption circulating fibrinogen was not measurably destroyed by any of the cannulae tested. Cannula platelet consumption was independent of cannula flow rate, platelet count, heparin anticoagulation, and ancrod defibrinogenation.

${ }^{111}$ In-platelet imaging of irradiated Silastic cannulae demonstrated luminal accumulation and subsequent embolization of irregular platelet masses. When irradiated Silastic cannulae were inserted as extension segments in the renal arteries of four animals the glomerular vessels became progressively occluded with nonfibrin-containing platelet thromboemboli. Nonirradiated Silastic cannulae in control arteries produced no significant vascular occlusion. Because the survival of platelets from animals with consumptive cannulae was not shortened in normal recipient animals we concluded that platelets were either irreversibly removed through thromboembolic consumption or unaffected in their viability.

Oral administration of dipyridamole and sulfinpyrazone decreased cannula platelet consumption in a dosedependent manner with complete interruption at 20 and $250 \mu \mathrm{mol} / \mathrm{kg}$ body wt per $\mathrm{d}$ (in three divided doses), respectively, whereas oral acetylsalicylic acid

Received for publication 15 January 1979 and in revised form 4 April 1979.
(10-330 $\mu \mathrm{mol} / \mathrm{kg}$ per d) had no measurable effect on cannula platelet consumption.

We conclude that this primate model simulates arterial thrombotic processes in man and that this model is suitable for the in vivo evaluation of biomaterials and of drugs that modify platelet behavior.

\section{INTRODUCTION}

Exposure of nonendothelialized surfaces to circulating blood initiates platelet and coagulation reactions that result in thrombosis (1-7). Initially, this process involves platelet adhesion, release of constituents, and aggregation to form an enlarging platelet mass (6-10). Arterial high shear conditions promote the formation of thrombus that is composed largely of platelets, whereas low shear venous flow conditions generate thrombin and fibrin with entrapment of erythrocytes $(8-10)$. Arterial blood flow also disrupts the accumulating platelet mass into fragments that may disaggregate or form platelet emboli (11-14). Because thrombosis represents a localized accumulation of hemostatic material, the nature of the process and rate of thrombus formation may be assessed kinetically in vivo by measuring the relative consumption of platelets and fibrinogen in its genesis (15-17). In this report we present the development of a baboon model of arterial thrombosis and thromboembolism that is quantitative, steady state, and reproducible such that the effects of modifying variables and therapies can be measured.

\section{METHODS}

Animals studied. 105 normal male baboons (Papio cynocephalus) were studied: 35 controls and 70 animals supporting femoral arteriovenous (A-V $)^{1}$ cannulae. The animals weighed $10-13 \mathrm{~kg}$ and had hematocrits of $35 \pm 3 \%( \pm 1 \mathrm{SD}){ }^{2}$

\footnotetext{
${ }^{1}$ Abbreviations used in this paper: ASA, acetylsalicyclic acid; A-V, arteriovenous.

2 Throughout this report variance about the mean is given as $\pm 1 \mathrm{SD}$.
} 
leukocyte counts of $5,000 \pm 1,200 / \mu l$, and platelet counts of $275,000 \pm 59,000 / \mu \mathrm{l}$. They were free of tuberculosis, dewormed, and observed to be disease free for at least $6 \mathrm{wk}$ before use. To facilitate repeated blood sampling permanent A-V cannulae were surgically placed in the femoral vessels and the animals were maintained in restraining chairs during the period of study (18). The permanent shunt system consisted of two 25-cm lengths of Silastic tubing, $2.8 \mathrm{~mm}$ i. d., (Dow Corning Corp., Midland, Michigan) connected to 13-15 guage Teflon (Dupont, E. I. deNemours \& Co., Inc., Wilmington, Del.) vessel tips (Lifemed, Vernitron Corp., Compton, Calif.). In addition, the two Silastic lengths were fixed with Dacron (Dupont, E. I. deNemours \& Co., Inc.) sewing cuffs at skin exit sites and connected with a $1-\mathrm{cm}$ length of blunt-edge Teflon $(2.8 \mathrm{~mm}$ i. d.). The cannulae were sterilized by autoclaving before surgical placement. Segments of test tubing were interposed between the segments of the permanent Silastic A-V shunt with $1-\mathrm{cm}$ long and 2.8-mm i. d., blunt-edged Teflon connectors. Usually four cannulations were performed on the femoral vessels of each baboon, thus permitting multiple reuse of each animal. The permanent Silastic connections with the artery and vein did not produce measurable platelet destruction (Table I).

Silastic tubing was rendered thrombogenic by a $10-15 \times 10^{6}$ rad dose of low voltage x-ray exposure over a 10-day period with an extracorporeal blood irradiation device that was developed for the experimental treatment of patients with refractory leukemia (19). In addition tubular polyurethane, 4.0 $\mathrm{mm}$ i. d. (Biomer, Ethicon, Inc., Somerville, N. J.), was also evaluated in the shunt system.

Cannula blood flow rate was measured noninvasively with a Doppler ultrasonic flowmeter (model 1503, Ward Associates, San Diego, Calif.) using whole blood for calibration. The instrument was equipped with an external "bobby pin" type transducer probe that fitted snugly around the Silastic tubing. In those cases where flow rate was measured, an average of three flow measurements were made per survival study. Measurements were reproducible to within about $10 \%$, and were averaged.

Laboratory studies. Platelet counts were measured with an electronic particle counter on peripheral blood collected in $4 \mathrm{mg} / \mathrm{ml}$ EDTA. Three to five platelet counts were performed for each study. The platelet count of 93 normal baboons was $279,000 / \mu \mathrm{l} \pm 55,000$. Platelet survival was determined by measurement of the disappearance of radioactivity from blood sampled 8-10 times after injection of autologous ${ }^{51} \mathrm{Cr}$-labeled platelets (20). The initial sample was drawn $1 \mathrm{~h}$ after the infusion of labeled platelets. In selected studies platelets were labeled with ["11'In]oxine (Diagnostic Isotope Laboratories, Bloomfield, N. J.) in Ringer's citrate dextrose plasma-free medium using about $1 \mathrm{mCi}$ per animal. The cannulae were imaged serially $(21,22)$.

Platelet survival time was analyzed by computer fitting to a gamma function and was $5.5 \pm 0.2 \mathrm{~d}$ in 35 normal male baboons $(23,24)$. The proportion of labeled platelets remaining within the systemic circulation after infusion (i.e., "recovery") was calculated from the platelet activity per milliliter, extrapolated to zero time, multiplied by the estimated blood volume, and divided by the platelet ${ }^{51} \mathrm{Cr}$ activity injected. Platelet turnover per microliter of blood per day, was calculated from the peripheral platelet count divided by the platelet survival time in days and corrected for recovery. Platelet recovery averaged $85 \pm 5 \%$ and platelet turnover was $59,000 \pm 7,000$ platelets $/ \mu \mathrm{l}$ per $\mathrm{d}$ in 35 normal male baboons. Overall platelet turnover in the animals was calculated by multiplying platelet turnover per milliliter by the estimated blood volume $(70 \mathrm{ml} / \mathrm{kg}$ body wt). In view of the steady-state requirement for the system of analysis we excluded studies in which the cannula became occluded during the period of observation.

In baboons with prosthetic A-V cannulae overall rates of platelet utilization may in general be mediated by: $(a)$ the rate of platelet adhesion and incorporation into thrombi at the blood-material interface; $(b)$ the rate of platelet incorporation into thrombi at sites distant from the bloodmaterial interface; $(c)$ the extent of reduction in residual lifespan of platelets that may continue to circulate; and $(d)$ the rate of senescent platelet removal through ordinary physiologic mechanisms. Because the relative contribution of each process of platelet elimination may depend significantly on the test situation, a mathematical model was used to allow separate estimation of the rate of senescent platelet removal, and the rate of overall platelet utilization induced directly or indirectly by the prosthetic cannula. Thereby the relationships between system variables and the rate of cannula-associated platelet consumption could be more readily assessed. This analysis used a "linear-exponential" model of platelet disappearance (25) and is expressed mathematically by:

$$
\tau=\frac{1-\mathrm{e}^{-5.5 \mathrm{k}}}{\mathrm{k}}
$$

where $\tau$ is the platelet survival time and $\mathrm{k}$ is a rate constant. The derivation and justification of this model is described in the Appendix.

For calculating fibrinogen turnover, the concentration of fibrinogen was estimated spectrophotometrically as thrombinclottable protein after collection on a glass rod and subsequent solution in alkaline urea (26). The fibrinogen concentration was $2.70 \pm 0.41 \mathrm{mg} / \mathrm{ml}$ in 63 normal baboons. Labeling of normal fibrinogen (prepared by ammonium precipitation technique) with ${ }^{125}$ I from normal donor animals was performed by the monoiodochloride method (27). Fibrinogen survival, derived from the least squares, computer determined half-time disappearance, and divided by the natural logarithm of 2 , averaged $2.6 \pm 0.2 \mathrm{~d}$ in 35 normal baboons. Fibrinogen turnover was calculated from the concentration of plasma fibrinogen divided by its mean survival time. Fibrinogen turnover averaged $1.0 \pm 0.10 \mathrm{mg} / \mathrm{ml}$ per $\mathrm{d}$ in 35 normal baboons.

Selected A-V cannulae were evaluated serially by scanning electron microscopy after variable exposure times to circulating blood. Specimens were perfused in situ with Hepes albumin buffer (4.6\% wt/vol glucose; $20 \mathrm{mM}$ Hepes, $\mathrm{pH} 7.4$; $4 \mathrm{~g} / 100 \mathrm{ml}$ bovine albumin) to remove free blood elements, followed by Karnovsky's fixative for $20 \mathrm{~min}$.

In four animals irradiated and nonirradiated Silastic cannulae were placed as $50-\mathrm{cm}$ extension segments in the right and left renal arteries, respectively. Blood flow and renal histology were studied. When blood flow through the renal artery fell to $<50 \mathrm{ml} / \mathrm{min}$, both kidneys were cleared of blood with Hepes albumin buffer for $30 \mathrm{~s}$ using in situ pressure perfusion followed by in vivo perfusion-fixation with halfstrength Karnovsky's fixative under $100 \mathrm{~cm}$ of hydrostatic pressure for $20 \mathrm{~min}(28)$. Samples were obtained from the proximal, central, and distal segments of the tubing and the kidneys were sampled at 20 random cortical sites. Tissue and cannular specimens for morphological study were subsequently placed in half-strength Karnovsky's solution for $4 \mathrm{~h}$ at $4^{\circ} \mathrm{C}$ and prepared for scanning or transmission electron microscopy. Material for transmission electron microscopy was postfixed with osmium tetroxide, embedded in Epon (Shell Chemical Co., Houston, Tex.), and cut. Initially, $1-\mu \mathrm{m}$-thick sections were mounted and stained with a polychromatic dye consisting of azure II-methylene, blue- 
basic fuchsin for light microscopic examination (29). They were subsequently prepared for transmission electron microscopy examination.

Heparin (Panheparin) and ancrod (Arvin) were obtained from Abbot Diagnostics, Diagnostic Products, Chicago, Ill.

Drugs mixed with apple sauce were administered orally to baboons bearing 47- $\mathrm{cm}^{2}$ irradiated Silastic cannulae in three divided doses in amounts shown in Table $\mathrm{V}$, beginning $3 \mathrm{~d}$ before platelet survival studies were begun and throughout the week of blood sampling. Dipyridamole was a gift from Boehringer-Ingelheim (Elmsford, New York) and sulfinpyrazone was a gift from CIBA-Geigy Corp., Pharmaceuticals Div., (Summit, N. J.).

\section{RESULTS}

\section{Characteristics of the cannula model}

Effect of permanent shunt. In 35 normal baboons the mean platelet survival time was $5.51 \pm 0.21 \mathrm{~d}$ (Table I). In 18 control animals with permanent Silastic shunts, platelet survival was not different $(5.44 \pm 0.32 ; P>0.75)$. On the average, this latter group of animals had undergone between one and two previous vessel cannulation procedures. Because the short permanent Silastic A-V shunt connecting the femoral vessels did not induce measureable platelet consumption, and the surgical variables were of little consequence in the model, test segments of tubing were subsequently connected between the two portions of the permanent Silastic shunt and measurements of cannula platelet consumption were attributed to the exposed luminal surface area of the test segment only.

When irradiated platelet consumptive Silastic shunts spontaneously thrombosed in another 12 animals platelet survival normalized $(5.47 \pm 0.44 ; P>0.75)$, cannula platelet consumption fell to zero and fibrinogen survival remained normal $(2.66 \pm 0.14 ; P>0.5)$.

Effect of cannula composition and surface area. Untreated Silastic was studied as extension segments of $66-$ and $132-\mathrm{cm}^{2}$ total luminal surface area in six animals each. Minimal changes in platelet survival times and cannula platelet consumption were observed because of the low reactivity of platelets for this material (Table I, Fig. 1).

In contrast, platelet survival was progressively shortened as the exposed area of irradiated Silastic or polyurethane was increased, but the relationship between platelet survival time and exposed surface area was nonlinear (Fig. 1). Theoretically the platelet survival time will approach zero asymptotically as the surface area becomes very large.

Calculations of cannula platelet consumption, however, correlated directly with exposed cannular area for both irradiated Silastic and polyurethane (Fig. 1). The quality of the correlations between shunt consumption and exposed surface area was determined from least-squares linear regression analysis and correlation coefficients for irradiated Silastic and polyurethane shunts were 0.940 and 0.901 , respectively; $P<0.001$.

Effect of time. Platelet survival measurements and the rates of cannula platelet consumption remained essentially constant for $8 \mathrm{wk}$ when serial measurements were carried out in animals with irradiated Silastic cannulae of area $47 \mathrm{~cm}^{2}$ (Table II). These observations demonstrated the constancy of platelet

TABLE I

Effect of Cannula Composition and Area on Platelet Consumption

\begin{tabular}{|c|c|c|c|c|c|c|c|}
\hline $\begin{array}{l}\text { Type and area of } \\
\text { cannula }\end{array}$ & $\begin{array}{c}\text { Number } \\
\text { of } \\
\text { animals }\end{array}$ & \multicolumn{3}{|c|}{ Platelet } & \multicolumn{3}{|c|}{ Cannula } \\
\hline Normal animals & 35 & $279,000 \pm 55,000$ & $5.51 \pm 0.21$ & $59,000 \pm 7,000$ & & & \\
\hline $\begin{array}{l}\text { Shunted animals } \\
\text { Untreated Silastic }\end{array}$ & 18 & $281,000 \pm 41,000$ & $5.44 \pm 0.32$ & $61,000 \pm 11,000$ & $0.07 \pm 0.02$ & 0.015 & $0.14 \pm 0.03$ \\
\hline 131.7 & 6 & $261,000 \pm 51,000$ & $4.00 \pm 0.29$ & $77,000 \pm 17,000$ & $2.8 \pm 0.7$ & 0.49 & $1.9 \pm 0.6$ \\
\hline \multicolumn{8}{|l|}{ Irradiated Silastic } \\
\hline 23.5 & 6 & $288,000 \pm 47,000$ & $3.52 \pm 0.39$ & $96,000 \pm 21,000$ & $4.58 \pm 0.7$ & 0.62 & $19.5 \pm 1.4$ \\
\hline 47 & 12 & $241,000 \pm 39,000$ & $2.11 \pm 0.32$ & $135,000 \pm 15,000$ & $9.36 \pm 0.5$ & 0.91 & $19.9 \pm 1.2$ \\
\hline 70.5 & 6 & $253,000 \pm 62,000$ & $1.51 \pm 0.19$ & $197,000 \pm 29,000$ & $14.7 \pm 1.6$ & 0.97 & $20.9 \pm 1.6$ \\
\hline 94 & 10 & $209,000 \pm 53,000$ & $1.04 \pm 0.11$ & $236,000 \pm 38,000$ & $18.1 \pm 1.2$ & 0.99 & $19.3 \pm 1.5$ \\
\hline
\end{tabular}

* Platelet reactivity index represents cannula platelet consumption per unit area $\left(\mathrm{cm}^{2}\right)$ of exposed luminal surface of the test cannulae. 


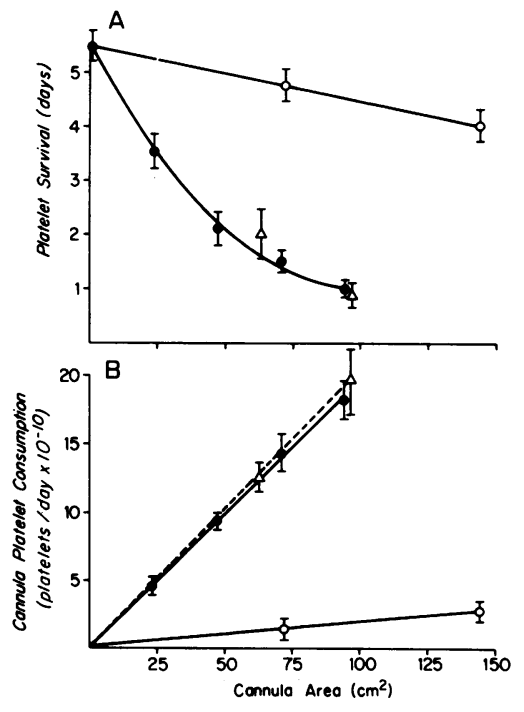

FIGURE 1 Relationships of cannular surface area, platelet survival, and cannula platelet consumption. Platelet survival shortens progressively in a nonlinear manner as the cannula area increases (A), whereas cannula platelet consumption correlates directly with exposed surface area (B) for untreated Silastic (open circles), irradiated Silastic (closed circles) and polyurethane (open triangles).

reactivity with this material on repeated testing (Table II). Additional studies (not shown) indicate that the irradiated Silastic shunts retained their rate of thrombogenicity unchanged for at least 6 mo of continuous use.

Fibrinogen kinetics and effect of anticoagulation. Simultaneous survival studies with ${ }^{51} \mathrm{Cr}$-platelets and ${ }^{125}$ I-fibrinogen in 21 animals supporting test shunts were compared with similar measurements in 35 normal animals (Table III). Fibrinogen survival and turnover in 10 animals bearing irradiated Silastic cannulae (luminal surface area of $47 \mathrm{~cm}^{2}$ ) were not different from 35 normal animals $(2.61 \pm 0.19 \mathrm{~d}$ and
$1.07 \pm 0.11 \mathrm{mg} / \mathrm{ml}$ per $\mathrm{d}$ vs. $2.60 \pm 0.20 \mathrm{~d}$ and $1.00 \pm 0.10$ $\mathrm{mg} / \mathrm{ml}$ per d, respectively) despite the greatly increased platelet turnover in the shunted animals (Table III). Fibrinogen kinetics were also carried out in nine selected shunt-bearing animals showing a range of cannula consumption rates varying from near 0 to 21.2 platelets $/ \mathrm{d} \times 10^{10}$. No significant change in fibrinogen survival or turnover was found among these animals $(P>0.50)$.

Moreover, heparin anticoagulation had no effect on either platelet or fibrinogen survival or turnover in seven animals bearing irradiated Silastic cannulae (Table III). These animals were given a bolus injection of 3,000 National Institutes of Health (NIH) U of heparin followed by continuous infusions of $35 \mathrm{U}$ of heparin/kg body wt per $\mathrm{h}$. This regimen uniformly increased the baboon whole blood clotting time from 5 to $>20$ min for the entire course of the study. In seven baboons, platelet consumption was $9.55 \pm 0.8$ $\times 10^{10}$ platelets $/ \mathrm{d}$ before heparinization and $9.09 \pm 1.0$ $\times 10^{10}$ platelets $/ \mathrm{d}$ after heparinization $(P>0.50)$.

In four additional studies, shunted animals were anticoagulated by enzymatic destruction of fibrinogen using ancrod (100 U initial bolus followed by $50 \mathrm{U}$ twice daily throughout the study). Ancrod depletion of circulating fibrinogen (fibrinogen concentrations were $<0.10 \mathrm{mg} / \mathrm{ml}$ ) had no effect on platelet kinetics or cannula platelet consumption $\left(10.3 \pm 1.2 \times 10^{10}\right.$ platelets/d, P $>0.50$; Table III).

Effect of blood flow rate. Shunt blood flow was measured noninvasively with a Doppler ultrasonic flowmeter in 21 animals with irradiated Silastic cannula of $47-\mathrm{cm}^{2}$ luminal surface and averaged $139 \pm 85 \mathrm{ml} / \mathrm{min}$ with a range of $40-220 \mathrm{ml} / \mathrm{min}$. In nine additional selected studies with other consumptive cannulae, no correlation was found between cannula blood flow rate and the rate of platelet consumption (correlation coefficient 0.084 ).

Effect of platelet count. Whereas the platelet

TABLE II

Effect of Time on Cannula Platelet Consumption

\begin{tabular}{|c|c|c|c|c|c|c|c|}
\hline \multirow[b]{3}{*}{ Time } & \multirow{3}{*}{$\begin{array}{c}\text { Number } \\
\text { of } \\
\text { animals }\end{array}$} & \multirow{2}{*}{\multicolumn{3}{|c|}{ Platelet }} & \multicolumn{3}{|c|}{ Cannula* } \\
\hline & & & & & \multirow{2}{*}{$\begin{array}{c}\text { Platelet } \\
\text { consumption }\end{array}$} & \multirow{2}{*}{$\begin{array}{l}\text { Fractional } \\
\text { turnover }\end{array}$} & \multirow{2}{*}{$\begin{array}{c}\text { Platelet } \\
\text { reactivity index }\end{array}$} \\
\hline & & Count & Survival & Turnover & & & \\
\hline serial wk & & 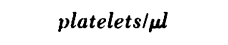 & $d$ & platelets/ul/d & platelets $/ d \times 10^{-10}$ & & platelets $/ \mathrm{cm}^{2} / \mathrm{d} \times 10^{8}$ \\
\hline 1 & 8 & $249,000 \pm 47,000$ & $2.27 \pm 0.31$ & $129,000 \pm 14,000$ & $8.75 \pm 0.81$ & 0.88 & $18.6 \pm 1.1$ \\
\hline 2 & 8 & $241,000 \pm 51,000$ & $2.14 \pm 0.24$ & $132,000 \pm 19,000$ & $9.18 \pm 0.77$ & 0.90 & $19.5 \pm 1.6$ \\
\hline 3 & 7 & $262,000 \pm 37,000$ & $2.34 \pm 0.36$ & $131,000 \pm 24,000$ & $8.82 \pm 0.70$ & 0.87 & $18.8 \pm 1.2$ \\
\hline 4 & 6 & $279,000 \pm 42,000$ & $2.31 \pm 0.29$ & $142,000 \pm 17,000$ & $9.56 \pm 0.92$ & 0.87 & $20.4 \pm 1.9$ \\
\hline 6 & 4 & $253,000 \pm 46,000$ & $2.19 \pm 0.33$ & $135,000 \pm 21,000$ & $9.35 \pm 0.85$ & 0.89 & $19.9 \pm 1.8$ \\
\hline 8 & 4 & $283,000 \pm 57,000$ & $2.40 \pm 0.27$ & $138,000 \pm 27,000$ & $9.18 \pm 0.89$ & 0.86 & $19.5 \pm 2.0$ \\
\hline
\end{tabular}

* $47 \mathrm{~cm}^{2}$ irradiated Silastic cannula.

\$ Cannula platelet consumption per unit area. 
TABLE III

Effect of Anticoagulation on Cannula Platelet Consumption

\begin{tabular}{|c|c|c|c|c|c|c|c|c|c|c|}
\hline \multirow[b]{3}{*}{ Study } & \multirow{3}{*}{$\begin{array}{c}\text { Number } \\
\text { of } \\
\text { animals }\end{array}$} & \multirow{2}{*}{\multicolumn{3}{|c|}{ Fibrinogen }} & \multirow{2}{*}{\multicolumn{3}{|c|}{ Platelet }} & \multicolumn{3}{|c|}{ Cannula* } \\
\hline & & & & & & & & \multirow{2}{*}{$\begin{array}{c}\text { Platelet } \\
\text { consumption }\end{array}$} & \multirow{2}{*}{$\begin{array}{c}\text { Fractional } \\
\text { turnover }\end{array}$} & \multirow{2}{*}{$\begin{array}{c}\text { Platelet } \\
\text { reactivity index } t\end{array}$} \\
\hline & & Conct. & Survival & Turnover & Count & Survival & Turnover & & & \\
\hline & & $m g / m l$ & $d$ & $m g / m l / d$ & 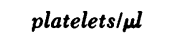 & $d$ & 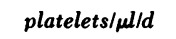 & platelets/d $\times 10^{-10}$ & & platelets/cm ${ }^{2} / d \times 10^{-8}$ \\
\hline Baseline & 10 & $2.78 \pm 0.47$ & $2.61 \pm 0.19$ & $1.07 \pm 0.11$ & $246,000 \pm 47,000$ & $2.11 \pm 0.24$ & $137,000 \pm 11,000$ & $9.55 \pm 0.8$ & 0.91 & $20.3 \pm 1.1$ \\
\hline Heparin & 7 & $2.88 \pm 0.39$ & $2.57 \pm 0.24$ & $1.12 \pm 0.09$ & $221,000 \pm 41,000$ & $2.02 \pm 0.29$ & $129,000 \pm 17,000$ & $9: 09 \pm 1.0$ & 0.92 & $19.3 \pm 1.2$ \\
\hline Ancrod & 4 & $<0.05$ & $<0.1$ & - & $269,000 \pm 59,000$ & $2.14 \pm 0.33$ & $147,000 \pm 24,000$ & $10.3 \pm 1.2$ & 0.90 & $21: 8 \pm 1.6$ \\
\hline
\end{tabular}

* $47 \mathrm{~cm}^{2}$ irradiated Silastic cannula

† Cannula platelet consumption per unit area.

counts in study animals generally remained within the range for normal animals (Tables I-III), some animals with irradiated Silastic shunts had steady-state platelet counts outside this range. No correlation was found between platelet count and cannula platelet consumption (correlation coefficient 0.146 ). Values for cannula platelet consumption in these animals remained constant because of a direct relationship between platelet survival times and platelet counts (correlation coefficient 0.926 ).

\section{Mechanism of cannula platelet consumption}

${ }^{111}$ In-platelets accumulated actively within segments of irradiated Silastic in a multifocal, irregular, and changing pattern (Fig. 2), whereas comparatively little radioactivity was present in the segments of untreated Silastic. Direct visualization by scanning electron

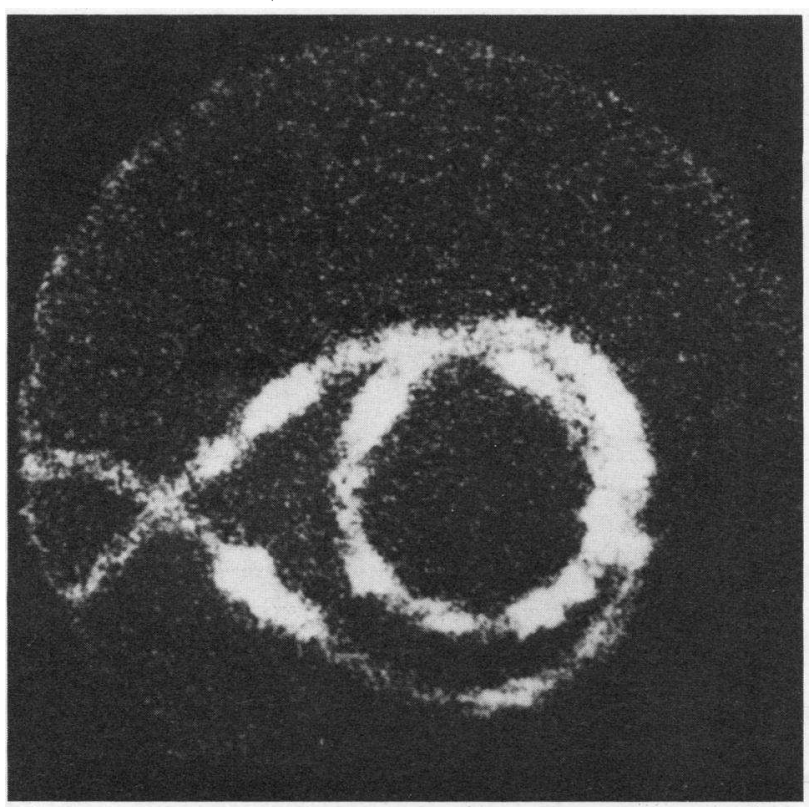

FigURE $2{ }^{111}$ In:platelet cannula imaging. ${ }^{111}$ In-labeled platelets accumulate in multifocal, irregular, and changing patterns because of ongoing thromboembolization. microscopy of the luminal surface of consumptive irradiated Silastic shunts verified the nonuniform accumulation of platelet material on the cannula with occasional leukocytes and adherent erythrocytes. Because "white" emboli were also occasionally observed macroscopically in operational shunts, the nonuniform and changing pattern of thrombus on the luminal surface appeared to represent regional loss of thrombus through embolization.

The nature of the microembolic material was examined in four baboons in which control and irradiated cannulae were interposed as segments in the renal arteries such that the renal microcirculation was used as a biological filter for embolic material. In these experiments irradiated or untreated Silastic cannulae were placed as extension segments in the right and left renal arteries, respectively, to serve as test and control shunts in the same experimental animal. Doppler transducer flow probes (Ward Associates) were attached to each shunt. Whereas renal blood flow did not change in the control vessel over the period of study, the irradiated Silastic cannula produced a progressive fall in renal artery blood flow from 220 to $<50 \mathrm{ml} / \mathrm{min}$ within $3 \mathrm{~h}$ (Fig. 3). When the kidneys were examined morphologically the small glomerular vessels were found to be occluded by

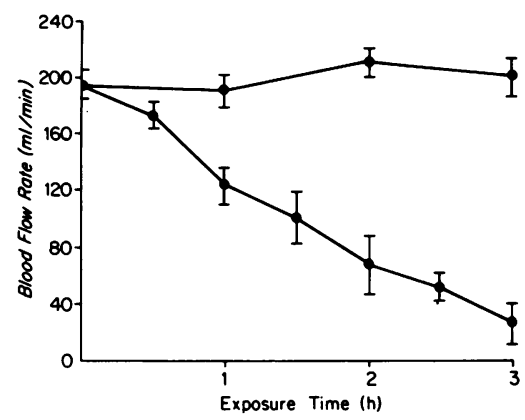

FIGURE 3 Progressive renal vascular occlusion. Renal blood flow falls progressively over $3 \mathrm{~h}$ when irradiated Silastic cannulae are interposed as segments in renal arteries. Untreated Silastic control segments in opposing renal arteries show no change in renal blood flow (upper plot). 


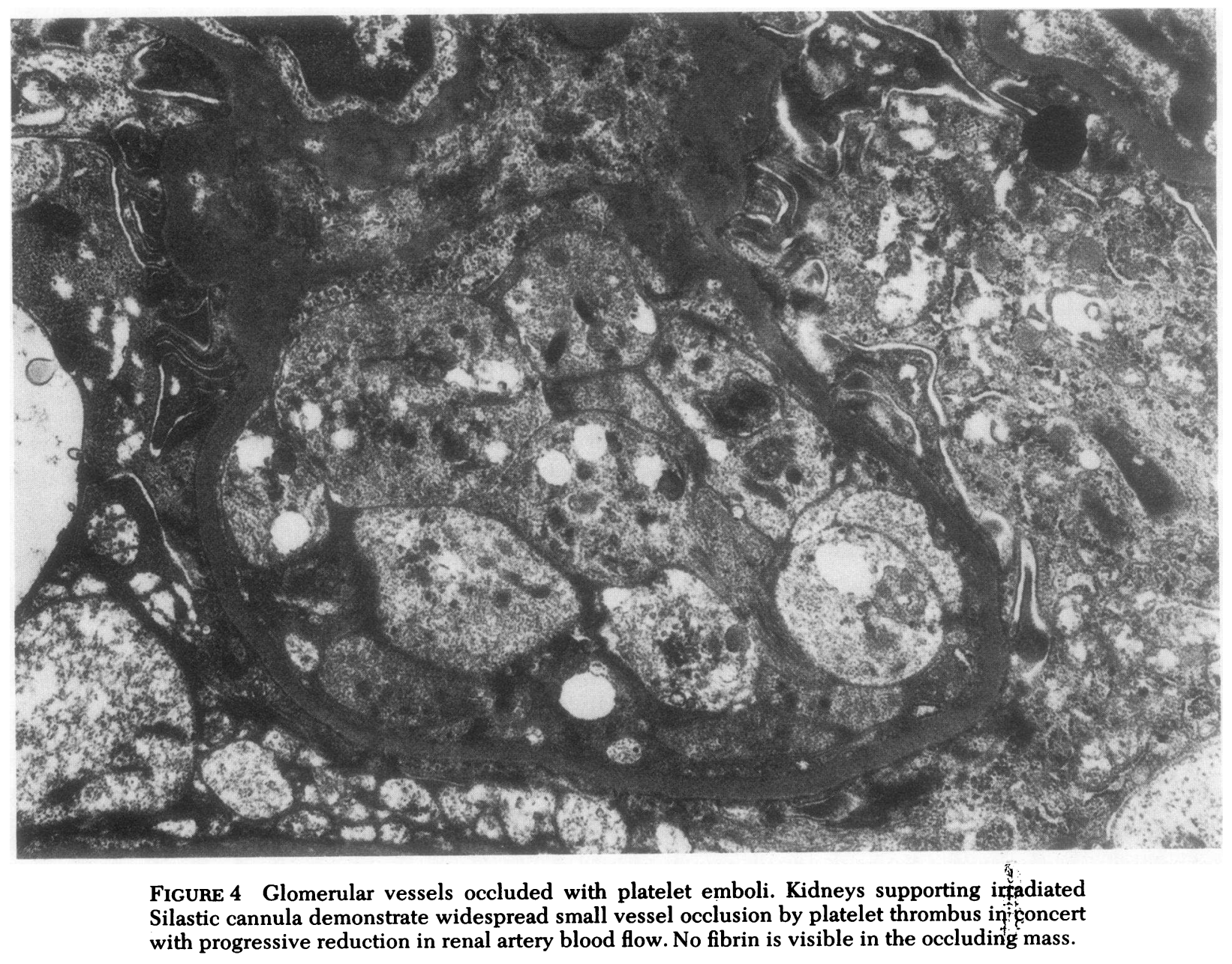

platelet thromboemboli (Fig. 4). Sections from control kidneys demonstrated the micro-circulation to be patent and essentially free of platelet thromboemboli.

The irreversibility of the platelet thromboembolic process was examined by a platelet cross-transfusion study involving five pairs of normal animals and animals bearing irradiated Silastic cannula (Fig. 5). None of these animals had been previously transfused. The base-line ${ }^{51} \mathrm{Cr}$-platelet survival and recovery measurements were $5.6 \pm 0.3 \mathrm{~d}$ and $83 \pm 6 \%$ compared with $2.3 \pm 0.3 \mathrm{~d}$ and $86 \pm 7 \%$ in the normal and shunted animals, respectively. During the subsequent week ${ }^{51} \mathrm{Cr}$-platelets from the shunt-bearing animals were injected into the normal recipients, whereas the ${ }^{51} \mathrm{Cr}$-platelets from the normal animals were injected into the cannula-bearing recipients for each of the five pairs. Despite repeated previous recirculation of platelets in the shunt bearing animals these platelets survived $5.4 \pm 0.4 \mathrm{~d}$ in the normal recipients. ${ }^{51} \mathrm{Cr}$-platelets from the normal donors survived $2.2 \pm 0.2 \mathrm{~d}$ in the shunted animals.

\section{Effect of drugs that modify platelet behavior}

The oral administration of dipyridamole decreased cannula platelet consumption in a dose-dependent manner (Table IV, Fig. 6) with complete interruption

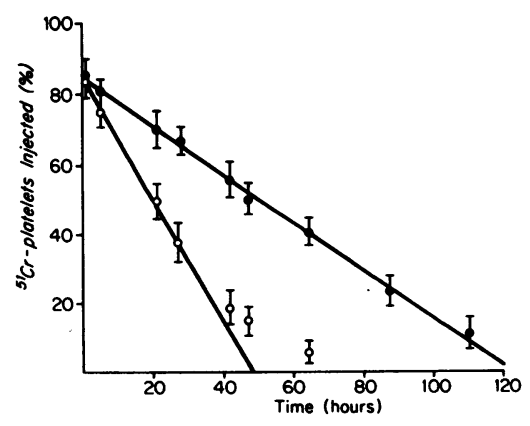

Figure 5 Platelet cross-transfusion study. ${ }^{51} \mathrm{Cr}$-platelets obtained from shunt-bearing animals survive normally in normal recipients (closed circles), whereas normal platelets show accelerated removal in shunt-bearing animals (open circles). 
TABLE IV

Effects of Pharmacologic Agents on Cannula Platelet Consumption

\begin{tabular}{|c|c|c|c|c|c|}
\hline \multirow{2}{*}{$\begin{array}{c}\begin{array}{c}\text { Drug study } \\
\text { in animals } \\
\text { with consumptive } \\
\text { cannulae }\end{array} \\
\mu m o l / k g / d\end{array}$} & \multirow[t]{2}{*}{$\begin{array}{c}\text { Number } \\
\text { of } \\
\text { animals }\end{array}$} & \multicolumn{2}{|c|}{$\begin{array}{l}\text { Platelet survival } \\
\text { time }\end{array}$} & \multicolumn{2}{|c|}{$\begin{array}{l}\text { Cannula platelet } \\
\text { consumption }\end{array}$} \\
\hline & & $d$ & & platelets $/ d \times 10^{-10}$ & \\
\hline Baseline & 12 & $2.11 \pm 0.32$ & & $9.36 \pm 0.5$ & \\
\hline \multicolumn{6}{|l|}{ Dipyridamole } \\
\hline 2 & 6 & $2.39 \pm 0.27$ & & $8.01 \pm 0.6$ & \\
\hline 10 & 6 & $3.71 \pm 0.34$ & $P<0.01$ & $4.62 \pm 0.42$ & $P<0.001$ \\
\hline 20 & 6 & $5.41 \pm 0.42$ & $P<0.001$ & $0.09 \pm 0.02$ & $P<0.001$ \\
\hline \multicolumn{6}{|l|}{ Sulfinpyrazone } \\
\hline 25 & 6 & $2.27 \pm 0.22$ & & $8.72 \pm 0.7$ & \\
\hline 125 & 6 & $3.52 \pm 0.40$ & $P<0.01$ & $4.83 \pm 0.51$ & $P<0.001$ \\
\hline 250 & 6 & $5.29 \pm 0.40$ & $P<0.001$ & $0.27 \pm 0.16$ & $P<0.001$ \\
\hline \multicolumn{6}{|l|}{ ASA } \\
\hline 10 & 6 & $2.34 \pm 0.24$ & $P>0.30$ & $8.90 \pm 0.77$ & $P>0.50$ \\
\hline 25 & 6 & $2.30 \pm 0.21$ & $P>0.30$ & $9.11 \pm 0.62$ & $P>0.50$ \\
\hline 167 & 6 & $2.26 \pm 0.19$ & $P>0.50$ & $9.08 \pm 0.70$ & $P>0.50$ \\
\hline 330 & 6 & $2.32 \pm 0.17$ & $P>0.50$ & $8.97 \pm 0.6$ & $P>0.50$ \\
\hline
\end{tabular}

of measurable cannula platelet consumption at 20 $\mu \mathrm{mol} / \mathrm{kg}$ body wt per $\mathrm{d}$ given in three divided doses. Oral sulfinpyrazone similarly reduced cannula platelet consumption in a dose-response fashion (Table IV, Fig. 6), but $250 \mu \mathrm{mol}$ of sulfinpyrazone/ $\mathrm{kg}$ body wt per $d$ (in three divided doses) was required to prevent measurable cannula platelet consumption. Oral acetylsalicylic acid (ASA) did not affect cannula platelet consumption significantly at doses of $10-330$ $\mu \mathrm{mol} / \mathrm{kg}$ body wt per $\mathrm{d}$.

\section{DISCUSSION}

Animal models of arterial thrombosis and embolization have had limited usefulness because the assessment of vascular occlusion has usually involved the use of experimental animals of questionable relevance to man with observations at a single point in time after an initiating vascular insult (30-32). Some of the uncontrolled variables that compromise the quantitative aspects of such approaches include the type and extent of the initial vascular injury, loss of thrombus by embolization, loss of thrombus by thrombolysis, hemodynamic characteristics of the model, and the timing and type of observations at sacrifice. To quantify continuously the overall rate of thrombus formation in vivo in a manner that is free of such variables, we used a primate model of $\mathrm{A}-\mathrm{V}$ cannula thrombosis. The choice of the baboon for these studies was based on the baboon's hemostatic similarity to man, together with its size, logistical ease of frequent blood sampling, and its long-term acceptance of chronically patent $A-V$ cannulae (18-20,33-35). Although it is difficult to establish equivalent thrombogenicity among man and other species, available evidence suggests that the baboon is a good animal for simulating arterial thrombotic processes in man. We have studied the hemostatic mechanism in the baboon and found it to resemble closely that of man in a number of respects, including concentrations of coagulation factors and plasminogen, bleeding time, platelet count, platelet volume, platelet morphology, platelet aggregation and release in vitro, and plasma levels of platelet factor 4, beta thromboglobulin, and fibrinopeptide A using human radioimmune assays $(18,20,36,37$, and unpublished observations).

In the present model arterial thrombogenesis is a process of selective platelet utilization that is quantified by calculating rates of cannula platelet con-

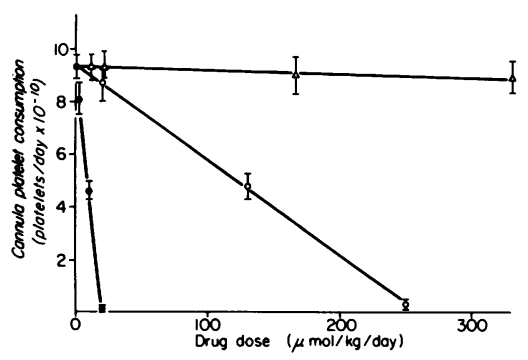

Figure 6 Drug effects on cannula platelet consumption. Oral dipyridamole (closed circles) and sulfinpyrazone (open circles) interrupt platelet consumption in a dose-dependent manner. ASA has no measureable effect on cannula platelet consumption in the doses tested (open triangles). 
sumption. The formation of platelet thrombus in this model does not measureably involve circulating fibrinogen and is unaffected by anticoagulation. This conclusion is based on the findings of normal fibrinogen survival times over widely varying rates of thrombotic cannula platelet consumption, and the ineffectiveness of anticoagulation by either heparin or defibrinogenation with ancrod to change cannula platelet consumption.

The baboon arteriovenous shunt model has several advantages over other in vivo test systems in common use today (31). Measurements of cannula platelet consumption in our studies are directly related to the area of exposed thrombogenic surface and are independent of normal variations in hematologic and hemodynamic variables. The determination of platelet survival curves allows essentially continuous measurement of the overall rate of thrombus formation, rather than a single determination of the local mass of thrombus present at a fixed point in time. The measurement of platelet consumption is quantitative and reproducible between different test animals, indicating that the rate of loss of adherent thrombus by thrombolysis and thromboembolism is not a significant variable between experiments. Also, because platelet survival is normal in baboons with permanent, short, Silastic arteriovenous shunts, the results of these studies are not compromised by possible surgical variables. Finally, this test system permits multiple and economic reuse of test animals that need not be sacrificed in the experiment.

There are several important considerations relating to the system of analysis used in these studies. First, platelet survival times were determined by least squares computer fitting to a gamma function that was independent of linear or exponential curve fitting bias and assumed only steady-state rates of platelet production and destruction, an assumption justified by the constancy of serial platelet counting $(23-26,38)$. Second, calculations of cannula platelet consumption involved the assumption that all platelets have a fixed life-span in control animals. This assumption also appeared to be valid based upon the linear disappearance pattern of mixed-population ${ }^{51} \mathrm{Cr}$-platelets in control baboons $(18,20,36,37$, and unpublished observations) and the finite life-span pattern with cohort labeling $(38,39)$. Finally, this method of analysis involves the assumption that platelet interactions with prosthetic cannulae either fail to affect viability or cause complete thrombotic removal. This assumption was justified by the results of crosstransfusion experiments (Fig. 5) and serial survival studies (Table II), which demonstrated that platelets taken from baboons with and without A-V cannulae: (a) survive normally in unshunted baboons, and (b) are consumed at identical rates in shunted animals. Thus, the cannula does not alter the residual sur- vival time of platelets which continue to circulate. Additional evidence is provided by the observation that when cannulae spontaneously thrombose or are removed during the course of a study, the mean lifespan of the remaining labeled platelets immediately normalizes (see Results).

When the data are analyzed according to the model presented here, the thrombogenicity of surfaces is characterized by the rate of platelet consumption per unit area (platelet reactivity index of Table I). For untreated Silastic, irradiated Silastic, and polyurethane shunts, this determination is strongly dependent on material type, yet is independent of variations in shunt length, platelet count and blood flow rate over fairly wide ranges of these variables. These data are consistent with the hypothesis that the rate of platelet arrival at the prosthetic surface by convective and diffusive mechanisms exceeds the rate at which platelets can be utilized by the surface. Mass transport effects are certainly not limiting. This model is, therefore, well suited for evaluating the thrombogenicity of prosthetic materials under arterial flow conditions.

In the present model, platelet thromboemboli form and embolize continuously from the thrombogenic luminal surface of the cannulae and the thromboembolic material is removed from circulation. Interestingly, the genesis of platelet thromboemboli does not involve detectable fibrin formation, as evidenced by the lack of fibrinogen utilization, inability of anticoagulation to modify the rate of thrombogenesis (Table III), and the morphological absence of fibrin in the occlusive renal emboli (Fig. 4). Although these observations do not exclude a fibrin-dependent mechanism underlying thrombus formation, an alternate mechanism for the formation of irreversible platelet masses must be considered. The results of the cross transfusion experiments indicate that thrombotic platelet consumption in this model is an all-or-none phenomenon rather than a process of cumulative platelet injury that progressively compromises viability (Fig. 5).

The three drugs dipyridamole, sulfinpyrazone, and ASA studied in the platelet thrombotic model have been shown to have clinical usefulness that has been attributed to their modifying effects on platelet behavior. Although ASA acts pharmacologically as a potent noncompetitive inhibitor of platelet cyclooxygenase through permanent acetylation (40), its lack of effect on platelet thrombus formation in the present model is apparently because of its inability to modify platelet adhesion and prevent degranulation of adherent platelets (41). Dipyridamole increases platelet cyclic AMP levels by inhibiting platelet phosphodiesterase, and thus appears to have increased efficacy in vivo through synergy with prostacyclin $\left(\mathrm{PGI}_{2}\right)$, which increases platelet cyclic AMP by stimulating platelet adenylcyclase (42). Because high 
doses of ASA inhibit prostacyclin production $(42,43)$, the combination of ASA and dipyridamole requires an evaluation of optimal dose combination $(42,44)$ for which the present animal model is well suited. Available in vitro evidence shows that sulfinpyrazone is a modestly potent inhibitor of platelet adhesion and platelet release (45). In the present thrombosis model (Table IV) this agent interrupts platelet thromboembolism at relatively higher doses by some mechanism unrelated to alterations in prostaglandin metabolism because ASA, a potent inhibitor of this system, has no measureable effect on cannula platelet consumption. Sulfinpyrazone's protective action on endothelium is an important additional effect in models that involve injury to the endothelium, such as homocysteinemia. ${ }^{3}$ The measurements of platelet and fibrinogen survival and turnover in patients with arterial thrombosis and thromboembolism have similarly shown selective platelet consumption that is interruptible with dipyridamole and sulfinpyrazone. Those groups of patients with documented shortening in platelet survival time and normal fibrinogen kinetics include ongoing arterial thromboembolism, cerebral vascular disease and transient ischemic attacks, artificial heart valves, prosthetic arterial grafts, diabetes mellitus, renal vascular disease, coronary artery disease, and homocystinuria $(16-18,38,46-48){ }^{3}$ In patients with artificial heart valves, the frequency of clinical emboli correlates directly with the exposed surface area of the prosthetic valves, and the capacity of dipyridamole to interrupt thrombotic consumption of ${ }^{51} \mathrm{Cr}$-platelets predicts the prevention of clinical thrombotic and thromboembolic episodes $(49,50)$.

On the basis of the available evidence we conclude that the baboon model simulates arterial thrombotic processes in man and that this model appears to be particularly useful for the in vivo evaluation of biomaterial thrombogenesis and the antithrombotic effects of platelet-modifying pharmacologic agents.

\section{APPENDIX}

Under the assumption of constant rates of platelet production and destruction the mean platelet survival time can be determined from the disappearance curve of a random sample of the parent population by means of the Mills-Dornhorst equation $(51,52)$, which states that when $t=0$, then

$$
\frac{\mathrm{d}}{\mathrm{dt}} \frac{\mathrm{c}(\mathrm{t})}{\mathrm{c}(0)}=-\frac{1}{\tau}
$$

i.e., the tangent to the platelet disappearance curve at $t=0$ intersects the time axis at $\tau$, the mean platelet survival time. The steady-state assumption can be verified by the constancy of multiple platelet counts, and Eq. 1 is generally con-

\footnotetext{
${ }^{3}$ Harker, L. A., R. Ross, R. T. Wall, and J. M. Harlan. Pharmacologic prevention of endothelial cell injury and homocysteine-induced arteriosclerosis. Submitted for publication.
}

sidered valid for the interpretation of survival data obtained with ${ }^{51} \mathrm{Cr}$-labeled platelets. In the present work it was assumed that platelet survival curves could be adequately described by an equation of the form:

$$
\frac{c(t)}{c(0)}=\frac{e^{-k t}-e^{-5.5 k}}{1-e^{-5.5 k}},
$$

and hence from Eq. 1:

$$
\tau=\frac{1-\mathrm{e}^{-5.5 \mathrm{k}}}{\mathrm{k}}
$$

These equations have been termed a linear-exponential model of platelet disappearance by Paulus (25). In this system it is assumed that in the absence of prosthetic cannulae $(\mathbf{k}=0)$ survival curves would be strictly linear, all cells having a fixed life-span of $5.5 \mathrm{~d}$. When prosthetic surfaces are present it is assumed that a fraction $k$ of the circulating platelet population will be destroyed at random each day. As $k$ becomes large, corresponding to the case in which relatively few platelets are removed via senescent mechanisms, survival curves approximate closely the exponential $e^{-k t}$ with $\tau=-1 / k$. In all cases the rate of cannula-associated platelet consumption (platelets/day) can be calculated by multiplying $\mathbf{k}$ times the total number of platelets in the circulation.

To test the applicability of this approach survival curves from 15 control animals and 68 baboons with a variety of prosthetic cannulae were fitted by a least-squares method to the general solution of the nonlinear differential equation:

$$
\frac{\mathrm{dc}(\mathrm{t})}{\mathrm{dt}}=\mathrm{ac} \mathrm{c}^{\mathrm{n}}
$$

with the order parameter $\mathbf{n}$ not restricted to integer values. This method has been described in greater detail elsewhere (53). Platelet survival times were determined using the method of Murphy (23) as described in the text, and results are shown in Fig. 7. As platelet survival time varies from about 5.5 to $2.5 \mathrm{~d}$, survival curves exhibit approximately linear $(n=0)$ to exponential $(n=1)$ behavior. Thus in 13 studies in which the platelet survival time exceeded $5.15 \mathrm{~d}$ the mean value of the order parameter $n$ was $0.092 \pm 0.040$. In 14 studies in which the platelet survival time was $<1.50 \mathrm{~d}$ the mean value of the order parameter $n$ was $1.011 \pm 0.059$. Although more general mathematical models have been developed in which cell survival curves need not exhibit strictly linear or strictly exponential behavior in the limiting cases, it has been shown elsewhere that departures from these assumptions of the order observed in the present studies will affect calculated values of cannula-associated platelet consumption by only a few percent (54). Thus the linear-exponential model, equation (3), appears adequate for

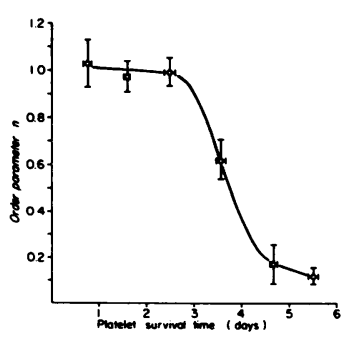

Figure 7 Order parameter of platelet survival curves. ${ }^{51} \mathrm{Cr}$ platelet disappearance curves vary from linear (zero order) in normal animals to exponential (first order) in animals with highly consumptive A-V cannulae. 
the calculation of rates of cannula platelet consumption given independent determinations of mean platelet survival times.

\section{ACKNOWLEDGMENTS}

We wish to thank Dr. J. C. Fanning and Dr. R. Ross, Dept. of Pathology, University of Washington, Seattle for the electron micrographs. Data analysis was carried out through the PROPHET System developed by the Chemical Biological Information Handling Program of the Biotechnology branch of the Division of Research Resources, National Institutes of Health.

This work was supported by research grants (HL-11775, HL-22163, HL-18645, and RR-00166) from the U. S. Public Health Service.

\section{REFERENCES}

1. Poole, J. C. F., J. E. French, and W. J. Cliff. 1963. The early stages of thrombosis. J. Clin. Pathol. (Lond.). 16: 523-528.

2. French, J. E., R. G. Macfarlane, and A. G. Sanders. 1964. The structure of haemostatic plugs and experimental thrombi in small arteries. Br.J. Exp. Pathol. 45: 467-474.

3. Spaet, T. H., and R. B. Erichson. 1966. The vascular wall in the pathogenesis of thrombosis. Thromb. Diath. Haemorrh. 21(Suppl.): 67.

4. Ashford, T. P., and D. G. Freiman. 1967. The role of the endothelium in the initial phases of thrombosis: an electron microscopic study. Am. J. Pathol. 50: 257-273.

5. Spaet, T. H., and C-H. Ts'ao. 1969. Vascular endothelium and thrombogenesis. In Thrombosis. S. Sherry, K. M. Brinkhous, E. Genton, and J. M. Stengle, editors. National Academy of Sciences, Washington, D. C. 416.

6. Baumgartner, H. R., and R. Muggli. 1976. Adhesion and aggregation: morphological demonstration and quantitation in vivo and in vitro. In Platelets in Biology and Pathology. J. L. Gordon, editor. Elsevier/North Holland Biomedical Press, Amsterdam. 21-60.

7. Hugues, J., and C. M. Lapiere. 1964. Nouvelles recherches sur l'accolement des plaquettes aux fibers de colagine. Thromb. Diath. Haemorrh. 11: 327.

8. French, J. E. 1969. The fine structure of experimental thrombi. In Thrombosis. S. Sherry, K. M. Brinkhous, E. Genton, and J. M. Stengle, editors. National Academy of Sciences, Washington, D. C. 300-320.

9. Mustard, J. F., and M. A. Packham. 1975. The role of blood and platelets in atherosclerosis and the complications of atherosclerosis. Thromb. Haemostasis. 33: 444-456.

10. Baumgartner, H. R., R. Muggli, T. B. Tschopp, and V. T. Turitto. 1976. Platelet adhesion, release and aggregation in flowing blood: effects of surface properties and platelet function. Thromb. Haemostasis. 35: 124138.

11. Fulton, G. P., R. P. Akers, and B. R. Lutz. 1953. White thromboembolism and vascular fragility in the hamster cheek pouch after anticoagulants. Blood. 8: 140-152.

12. Honour, A. J., and R. W. Ross Russell. 1962. Experimental platelet embolism. Br.J. Exp. Pathol. 43: 350-362.

13. Jørgensen, L., H. C. Rowsell, T. Hovig, M. F. Glynn, and J. F. Mustard. 1967. Adenosine diphosphate-induced platelet aggregation and myocardial infarction in swine. Lab. Invest. 17: 616-644.

14. Haerem, J. W. 1974. Mural platelet microthrombi and major acute lesions of main epicardial arteries in sudden coronary death. Atherosclerosis. 19: 529-541.
15. Adelson, E., J. J. Rheingold, O. Parker, A. Beunaventura, and W. H. Crosby. 1961. Platelet and fibrinogen survival in normal and abnormal states of coagulation. Blood. 17: 267-281.

16. Harker, L. A., and S. J. Slichter. 1972. Platelet and fibrinogen consumption in man. N. Engl. J. Med. 287: 999-1005.

17. Harker, L. A., and S. J. Slichter. 1974. Arterial and venous thromboembolism: kinetic characterization and evaluation of therapy. Thrombos. Diath. Haemorrh. 31: 188-203.

18. Harker, L. A., S. J. Slichter, C. R. Scott, and R. Ross. 1974. Homocystinemia: vascular injury and arterial thrombosis. N. Engl. J. Med. 291: 537-543.

19. Storb, R., H. Ragde, and E. D. Thomas. 1969. Extracorporeal irradiation of the blood in baboons. Radiat. Res. 38: 43-54.

20. Harker, L. A., R. Ross, S. Slichter, and C. Scott. 1976. Homocystine-induced arteriosclerosis: the role of endothelial cell injury and platelet response in its genesis. J. Clin. Invest. 58: 731-741.

21. Thakur, M. L., M. Welsh, J. H. Joist, and R. E. Coleman. 1976. Indium-111 labeled platelets: studies on preparation and evaluation of in vitro and in vivo functions. Thromb. Res. 9: 345-357.

22. Goodwin, D. A., J. T. Bushberg, P. W. Doherty, M. J. Lipton, F. K. Conley, C. I. Diamarti, and C. F. Meares. 1978. Indium-111-labeled autologous platelets for location of vascular thrombi in humans. J. Nucl. Med. 19: 626-634.

23. Murphy, E. A., and M. E. Francis. 1971. The estimation of blood platelet survival. II. The multiple hit model. Thromb. Diath. Haemorrh. 25: 53-80.

24. Paulus, J. M. 1971. Platelet Kinetics: Radioisotopic, Cytological, Mathematical and Clinical Aspects. NorthHolland Publishing Company, Amsterdam. 360.

25. Paulus, J. M. 1974. Production et Destruction des Plaquettes Sanguines, Masson et Cie Editors, Paris. 56.

26. Jacobsson, K. 1955. Studies on the determination of fibrinogen in human blood plasma. Scand. J. Clin. Lab. Invest. 7(Suppl. 14): 7-54.

27. Takeda, Y. 1966. Studies of the metabolism and distribution of fibrinogen in healthy men with autologous ${ }^{125} \mathrm{I}$ labeled fibrinogen. J. Clin. Invest. 45: 103-111.

28. Haudenschild, C., H. R. Baumgartner, and A. Studer. 1972. Significance of fixation procedure for preservation of arteries. Experientia (Basel). 28: 828-831.

29. Huber, J. D., F. Parker, and G. F. Odland. 1968. A basic fuchsin and alkalinized methylene blue rapid stain for epoxy-embedded tissue. Stain Technol. 43: 83-87.

30. Sherry, S., K. M. Brinkhous, E. Genton, and J. M. Stengle, editors. 1969. In Thrombosis. National Academy of Sciences, Washington, D. C.

31. Didisheim, P. 1972. Animal models useful in the study of thrombosis and anti-thrombotic agents. Prog. Hemostasis Thromb. 1: 165-197.

32. Migaki, G., and H. W. Casey. 1976. Animal Models of Thrombosis and Hemorrhagic Diseases. Department of Health, Education and Welfare, Public Health Service, National Institutes of Health. DHEW No. 76-982. 55-65.

33. Hampton, J. W., and C. Matthews. 1966. Similarities between baboon and human blood clotting. J. Appl. Physiol. 21: 1713-1716.

34. Todd, M. E., E. McDevitt, and E. I. Goldsmith. 1972. Blood-clotting mechanisms of nonhuman primates: choice of the baboon model to simulate man. J. Med. Primatol. 1: 132-141. 
35. Rodman, N. F., R. H. Wolf, and R. G. Mason. 1974. Venous thrombosis on prosthetic surfaces: evolution and blood coagulation studies in a nonhuman primate model. Am. J. Pathol. 75: 229-242.

36. Harker, L. A., S. J. Slichter, and L. R. Sauvage. 1977. Platelet consumption by arterial prosthesis: the effects of endothelialization and pharmacologic inhibition of platelet function. Ann. Surg. 186: 594-601.

37. Koerker, D. J., L. A. Harker, and C. J. Goodner. 1975. Effects of somatostatin on hemostasis in baboons. $N$. Engl. J. Med. 293: 476-479.

38. Harker, L. A. 1978. Platelet survival time: Its measurement and use. Prog. Hemostasis Thromb. 4: 321-347.

39. Ginsburg, A. D., and R. H. Aster. 1969. Kinetic studies with ${ }^{51}$ chromium-labeled platelet cohorts in rats. J. Lab. Clin. Med. 74: 138-144.

40. Roth, G. J., and P. W. Majerus. 1975. The mechanism of the effects of aspirin on human platelets. I. Acetylation of a particulate fraction protein. J. Clin. Invest. 56: 624632.

41. Weiss, H. J., T. B. Tschopp, and H. R. Baumgartner. 1975. Impaired interaction (adhesion-aggregation) of platelets with the subendothelium in storage-pool disease and after aspirin ingestion. A comparison with von Willebrand's disease. N. Engl. J. Med. 293: 619-623.

42. Moncada, S., and R. Korbut. 1978. Dipyridamole and other phosphodiesterase inhibitors act as antithrombotic agents by potentiating endogenous prostacyclin. Lancet. I: $1286-1289$.

43. Roth, G. J., and P. W. Majerus. 1975. Acetylation of prostaglandin synthetase by aspirin. Proc. Natl. Acad. Sci. U. S. A. 72: 3073-3076.

44. Kelton, J. G., J. Hirsh, C. J. Carter, and M. R. Buchanan. 1978. Thrombogenic effect of high-dose aspirin in rabbits. Relationship to inhibition of vessel wall synthe- sis of prostaglandin $\mathrm{I}_{2}$-like activity. J. Clin. Invest. 62: $892-895$.

45. Cazenave, J. P., M. A. Packham, M. A. Guccione, and J. F. Mustard. 1974. Inhibition of platelet adherence to a collagen coated surface by nonsteriodal anti-inflammatory drugs, pyrimido-pyrimidine and tricyclic compounds and lidocaine. J. Lab. Clin. Med. 83: 797-806.

46. Steele, P., H. Weily, H. Davies, G. Pappas, and E. Genton. 1975. Platelet survival time following aortic valve replacement. Circulation. 51: 358-362.

47. Ritchie, J. L., and L. A. Harker. 1977. Platelet and fibrinogen survival in coronary atherosclerosis: response to medical and surgical therapy. Am. J. Cardiol. 39: 595598.

48. Steele, P., J. Carrol, D. Overfield, and E. Genton. 1977. Effect of sulfinpyrazone on platelet survival time in patients with transient cerebral ischemic attacks. Stroke. 8: $396-398$.

49. Harker, L. A., and S. J. Slichter. 1970. Studies of platelet and fibrinogen kinetics in patients with prosthetic heart valves. N. Engl. J. Med. 283: 1302-1305.

50. Sullivan, J. M., D. E. Harken, and R. Gorlin. 1971. Pharmacologic control of thrombo embolic complications of cardiac-valve replacement. N. Engl.J. Med. 284: 13911394.

51. Mills, J. N. The lifespan of the erythrocyte. 1946. J. Physiol. 105: 16P-17P.

52. Dornhorst, A. C. 1951. The interpretation of red cell survival curves. Blood. 6: 1284-1292.

53. Simon, T. L., T. M. Hyers, J. P. Gaston, and L. A. Harker. 1978. Heparin pharmacokinetics: increased requirements in pulmonary embolism. Br. J. Haematol. 39: 111-120.

54. Hanson, S. R. 1977. In vivo evaluation of biomaterial thrombogenesis. Ph.D. Dissertation, University of Washington, Seattle. 